
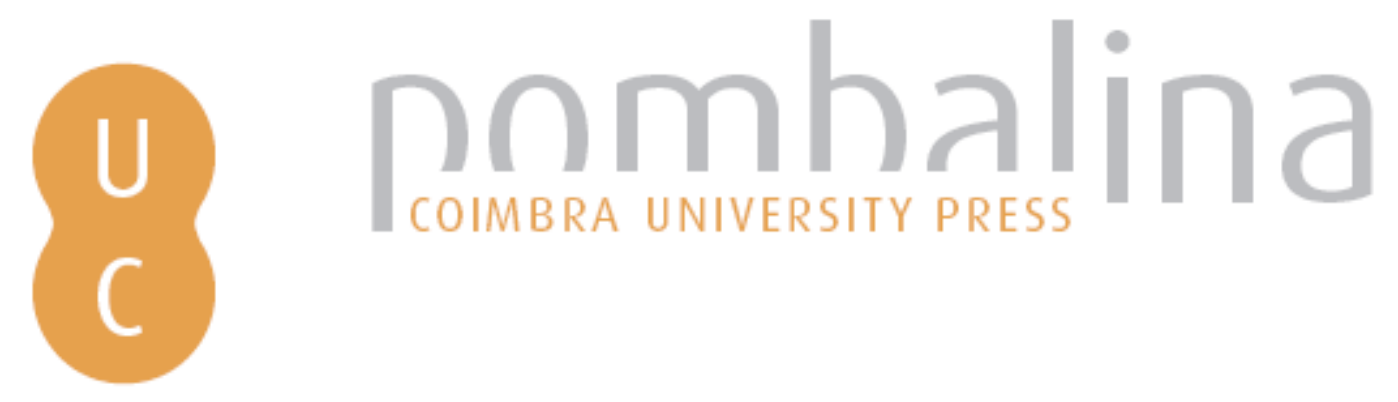

\title{
Águas minerais de Trás-os-Montes e Alto Douro (NE de Portugal): sistematização e aproveitamentos
}

\author{
Autor(es): $\quad$ Oliveira, A. Sousa; Almeida, S. M. S.; Reis, A. R.; Alencoão, A. M. P.; \\ Sousa, L. M. O.; Lourenço, J. M. M. \\ Publicado por: Imprensa da Universidade de Coimbra \\ URL \\ persistente: \\ URI:http://hdl.handle.net/10316.2/31478 \\ DOI: \\ DOl:http://dx.doi.org/10.14195/978-989-26-0534-0_42; DOI:978-989-26- \\ 0534-0 (PDF) \\ Accessed : $\quad$ 26-Apr-2023 08:07:35
}

A navegação consulta e descarregamento dos títulos inseridos nas Bibliotecas Digitais UC Digitalis, UC Pombalina e UC Impactum, pressupõem a aceitação plena e sem reservas dos Termos e Condições de Uso destas Bibliotecas Digitais, disponíveis em https://digitalis.uc.pt/pt-pt/termos.

Conforme exposto nos referidos Termos e Condições de Uso, o descarregamento de títulos de acesso restrito requer uma licença válida de autorização devendo o utilizador aceder ao(s) documento(s) a partir de um endereço de IP da instituição detentora da supramencionada licença.

Ao utilizador é apenas permitido o descarregamento para uso pessoal, pelo que o emprego do(s) título(s) descarregado(s) para outro fim, designadamente comercial, carece de autorização do respetivo autor ou editor da obra.

Na medida em que todas as obras da UC Digitalis se encontram protegidas pelo Código do Direito de Autor e Direitos Conexos e demais legislação aplicável, toda a cópia, parcial ou total, deste documento, nos casos em que é legalmente admitida, deverá conter ou fazer-se acompanhar por este aviso.

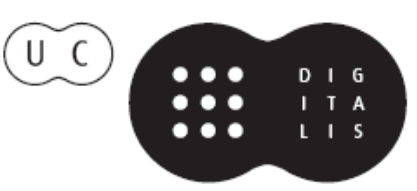





\title{
ÁGUAS MINERAIS DE TRÁS-OS-MONTES E ALTO DOURO (NE DE PORTUGAL): SISTEMATIZAÇÃO E APROVEITAMENTOS
}

\author{
MINERAL WATERS OF THE TRÁS-OS-MONTES \\ E ALTO DOURO REGION (NE OF PORTUGAL): \\ SYSTEMATIZATION AND EXPLOITATION
}

\author{
A. Sousa Oliveira' ${ }^{1}$, S. M. S. Almeida ${ }^{2}$, \\ A. R. Reis ${ }^{1}$, A. M. P. Alencoão ${ }^{1}$, \\ L. M. O. Sousa ${ }^{3} \&$ J. M. M. Lourenço
}

\begin{abstract}
Resumo - Na região de Trás-os-Montes e Alto Douro (NE de Portugal continental) existe um vasto leque de ocorrências hidrominerais com tipologia hidroquímica diversificada, cuja origem e localização são condicionadas principalmente por fatores geológicos/ geomorfológicos. A variedade de aproveitamentos atualmente existente e a disponibilidade deste recurso hidromineral, quer em diversidade, quer em quantidade, aponta para um recurso geológico que, explorado de uma forma sustentada nas suas múltiplas valências, poderá contribuir e estimular o desenvolvimento sócio-económico da região.
\end{abstract}

Palavras-chave - Águas minerais; Recursos hidrominerais; Geotermia; Termalismo; Aproveitamentos

Abstract - In Trás-os-Montes e Alto Douro region (NE of Portugal) there are several mineral water springs of diverse hydrochemical types whose origin and location are mainly

\footnotetext{
1 Universidade de Trás-os-Montes e Alto Douro, ECVA, Dep. de Geologia, Ap. 1013, 5001-801 Vila Real, Portugal; Centro de Geofísica da Universidade de Coimbra, Av. Dr. Dias da Silva, 3000-134 Coimbra, Portugal; soliveir@utad.pt; anarreis@utad.pt; alencoao@utad.pt

2 Doutoranda na FEUP. Un. do Porto, Rua Dr. Roberto Frias, s/n 4200-465 Porto, Portugal; sms.almeida@netcabo.pt

3 Universidade de Trás-os-Montes e Alto Douro, ECVA, Dep. de Geologia, Ap. 1013, 5001-801 Vila Real, Portugal; Centro Geociências da Un. Coimbra, Lgo M. Pombal 3000-272 Coimbra, Portugal; lsousa@utad.pt; martinho@utad.pt
} 
conditioned by geologicallgeomorphological factors. The variety of current utilizations and availability of this hydromineral resource, either in diversity or in quantity, shows that this geological resource exploited in a sustainable way in its multiple valences can contribute and stimulate the socio-economic development of the region.

Keywords - Mineral waters; Hydromineral resources; Geothermal resources; Spa; Uses

\section{1 - Introdução}

Desde os tempos mais remotos, o Homem tem utilizado as águas nas mais diversas funçôes. Perde-se no tempo o culto das águas, em particular o das águas minerais, às quais se têm associado propriedades milagrosas na prevenção e cura de enfermidades. Atualmente, a razão de ser destas propriedades milagrosas é justificada cientificamente pelas características físico-químicas destas águas, cujos estudos médico-hidrológicos e práticas termais têm demonstrado a existência de efeitos terapêuticos ao nível de várias afeçôes.

A utilização mais comum tem sido feita ao nível do termalismo terapêutico, contudo, atualmente, têm-se vindo a oferecer e a procurar implementar programas de termalismo de bem-estar, domínio importante com procura em crescendo. Dependendo ainda das suas características, o aproveitamento tem-se ainda dirigido para o engarrafamento e na produçáo de calor para aquecimento de espaços edificados, de águas sanitárias e de estufas, entre outros.

O valor patrimonial, por vezes elevado, associado às ocorrências, náo só relativo aos valores naturais mas também à carga histórica das edificaçóes associadas a algumas emergências, é ainda elemento suscetível de ser integrado como oferta turística singular.

A diversidade de tipologias e de ocorrências de águas minerais no território transmontano-duriense (NE de Portugal continental) colocam-no numa situação de riqueza hidromineral impar a nível nacional pelo que, neste documento, se pretende divulgar, de um modo simples e sintético, aspetos deste recurso geológico cujo aproveitamento adequado poderá contribuir para o desenvolvimento económico-social deste território.

\section{$2-$ As águas minerais e a geologia}

As águas minerais são um recurso natural que, segundo a legislação portuguesa, Decreto-Lei 90/90 de 16 de Março, se enquadram no domínio dos recursos geológicos e, dentro deste, no domínio dos recursos hidrominerais. Uma água é designada mineral natural se for "bacteriologicamente própria, de circulaçáo profunda, com particularidades físico-químicas estáveis na origem dentro da gama de flutuaçóes naturais, de que resultam propriedades terapêuticas ou simplesmente efeitos favoráveis à saúde" ( $\mathrm{n}^{\circ} 2$, art. $3^{\circ}$, Decreto-Lei 90/90 de 16 de Março).

As águas minerais, sendo de circulaçáo subterrânea, estâo em contacto por um período de tempo com as rochas por onde passam. No caso concreto, as águas minerais de Trás-os-Montes e Alto Douro são principalmente de origem meteórica, isto é, resultam da água da chuva que se infiltrou profundamente (MARQUES, 1999; SOUSA 
OLIVEIRA, 2001; ANDRADE, 2002). No percurso no subsolo, desde o local onde se inicia a infiltração até ao local da emergência, a água efetuou um circuito, com uma determinada profundidade, que pode atingir vários milhares de metros, e foi reagindo com as rochas encaixantes a uma determinada temperatura, que na situação em causa resulta principalmente da difusão térmica a partir do manto (MARQUES, 1999; SOUSA OLIVEIRA, 2001).

As características físico-químicas dessa água, como o $\mathrm{pH}$, a temperatura, a mineralização total e a natureza dos componentes iónicos, entre outros, dependem do contexto litoestrutural e tectónico enquadrante do circuito hidromineral, da profundidade atingida, do tempo de residência, da velocidade de fluxo e da estabilidade das suas características até à emergência, da comunidade microbiológica associada, etc.

Ao reagir com as rochas, a água adquire componentes inerentes às suas composiçôes mineralógicas, pelo que de rochas diferentes resultam águas com características diferentes. Segundo SOUSA OLIVEIRA (2001), a principal reação química envolvida no fenómeno de interação água-rocha é a hidrólise dos minerais silicatados, presentes nas rochas ígneas e metamórficas da região, que é facilitada pela presença de ácido carbónico $\left(\mathrm{H}_{2} \mathrm{CO}_{3}\right)$, que resulta da reação $\mathrm{CO}_{2}+\mathrm{H}_{2} \mathrm{O} \leftrightarrow \mathrm{H}_{2} \mathrm{CO}_{3}$. Este $\mathrm{CO}_{2}$ pode ter várias origens: atmosférica, do solo/subsolo ou do manto, entre outras. A expressão geral que traduz a hidrólise dos aluminossilicatos primários (BRICKER et al., 1968) pode escrever-se como alumin. prim. ${ }^{\text {ios }}+$ $+\mathrm{H}_{2} \mathrm{O}+\mathrm{CO}_{2} \rightarrow$ sólidos ricos em $\mathrm{Al}+$ catióes livres $+\mathrm{HCO}_{3}{ }^{-}+\mathrm{H}_{4} \mathrm{SiO}_{4}$. Resulta, assim, a formação de minerais secundários (por exemplo, minerais de argila e óxidos de ferro) e a libertação para a solução do anião $\mathrm{HCO}_{3}{ }^{-}$, de catiôes $\left(\mathrm{Na}^{+}, \mathrm{Ca}^{2+}\right.$, etc., dependendo da composição do aluminossilicato primário) e de sílica $\left(\mathrm{H}_{4} \mathrm{SiO}_{4}\right)$. As reaçóes de dissoluçáo de alguns dos minerais silicatados mais comuns das rochas ígneas e metamórficas podem, deste modo, explicar a composição química das águas associadas, especialmente no que respeita à composição em elementos maiores.

O tempo que a água interage com a rocha também é fundamental para a mineralização. Esta, normalmente está na razão direta com esse tempo de interação, que pode ser da ordem dos milhares de anos, pelo que águas atualmente em exploração podem ter-se infiltrado nos princípios do Holocénico, neste caso pode ir até há mais ou menos 10.000 anos (SOUSA OLIVEIRA, 2001).

A temperatura é também um fator favorável no processo de interação água-rocha, sendo que maiores temperaturas ocasionam normalmente águas mais mineralizadas. A temperatura de emergência é inferior, na maioria dos casos bastante inferior, à temperatura máxima atingida no reservatório; esta vai decaindo ao longo do circuito hidráulico ascendente. A título de exemplo, MARQUES (1999) aponta temperaturas de reservatório da ordem de $100{ }^{\circ} \mathrm{C}$ a $120^{\circ} \mathrm{C}$ para as águas gasocarbónicas da regiáo situada entre Vila Pouca de Aguiar e Vilarelho da Raia, com temperaturas de emergência da ordem dos $16^{\circ} \mathrm{C}$ para as águas não termais e da ordem dos $73^{\circ} \mathrm{C}$ para as águas termais.

A comunidade microbiológica, que faz parte integrante da composição das águas minerais, poderá também contribuir especificamente para a diversidade e especialização da riqueza hidromineral.

Assim, constata-se que a natureza das águas minerais é tão diversa quanto a diversidade de parâmetros intervenientes no circuito hidromineral, e é esta diversidade que determina a riqueza do património hidromineral de Trás-os-Montes e Alto Douro. 


\section{3 - Ocorrências e tipologias hidroquímicas e a geologia da região}

$\mathrm{Na}$ área geográfica enquadrada na região de Trás-os-Montes e Alto Douro registam-se inúmeras ocorrências de águas minerais de natureza diversificada, que se podem integrar em 22 pólos hidrominerais principais (Fig. 1, Tabela 1).

O fator geologia é o principal responsável na determinação daquela diversificação, pelo que Trás-os-Montes e Alto Douro é das regiōes do país onde esta diversidade é mais significativa.

Os diferentes litótipos enquadram-se temporalmente desde o Pré-Câmbrico até à atualidade, e distribuem-se num espetro litológico muito variado, que integra rochas granitóides, metassedimentares, vulcanossedimentares, bem como rochas exóticas (básicas e ultrabásicas), associadas a complexos ofiolíticos, e também rochas sedimentares recentes.

As grandes estruturas tectónicas, nomeadamente as zonas de falha, de que se destacam as zonas de falha de Vila Real-Verín e de Bragança-Unhais da Serra, bem como as grandes estruturas de carreamento, são determinantes no enquadramento físico dos sistemas hidrominerais de Trás-os-Montes e Alto Douro (Fig. 1).

Nesta região, a localização dos diferentes pólos hidrominerais e das suas emergências, resulta da conjugação de fatores geomorfológicos, litológicos, estruturais e geotectónicos, de que se destacam as zonas geomorfologicamente depressionadas, os vales de fraturas extensas, o contacto entre rochas granitóides e metassedimentares, os domínios intra ou peribatolíticos, os domínios intrametassedimentares, mas onde a tipologia das águas minerais está geneticamente associada a ambientes granitóides ocorrentes em profundidade, e as áreas com litótipos de natureza básica e/ou ultrabásica.

Decorrente do que anteriormente se referiu, é natural que existam águas minerais de tipologia muito diversificada. Assim, considerando diferentes aspetos de natureza físico-química, as águas minerais de Trás-os-Montes e Alto Douro podem integrar-se em 5 famílias hidroquímicas principais (Fig. 1; Tabela 1), sendo que dentro de cada família cada emergência pode apresentar água com características muito particulares (PORTUGAL FERREIRA \& SOUSA OLIVEIRA, 2000; SOUSA OLIVEIRA, 2001) que resultam naturalmente da multiplicidade de variáveis intervenientes no processo de mineralização:

a) família 1 ( $\star$ ) bicarbonatada, sódica, maioritariamente gasocarbónica, fluoretada, frequentemente ferruginosa e normalmente ácida;

b) família $2(\diamond)$ bicarbonatada, sódica, sulfúrea, fluoretada, por vezes cloretada e alcalina;

c) família $3(\odot)$ bicarbonatada/carbonatada, sódica, sulfúrea, silicatada e hiperalcalina;

d) família $4(\nabla)$ bicarbonatada, sódica, sulfúrea, hipossilicatada e alcalina;

e) família 5 ( $\mathbf{\Delta}$ ) bicarbonatada, sódica, sulfatada, sulfúrea, hipossalina e alcalina.

Em termos aniónicos, a componente bicarbonatada é dominante, estando presente em todas as famílias; contudo, na família 3, é partilhada com a componente carbonatada. Nesta última família, as águas são simultaneamente hiperalcalinas, e enquadram-se em ambientes litológicos de natureza básica e/ou ultrabásica ocorrentes nas regiōes de Bragança, Morais e Macedo de Cavaleiros. 


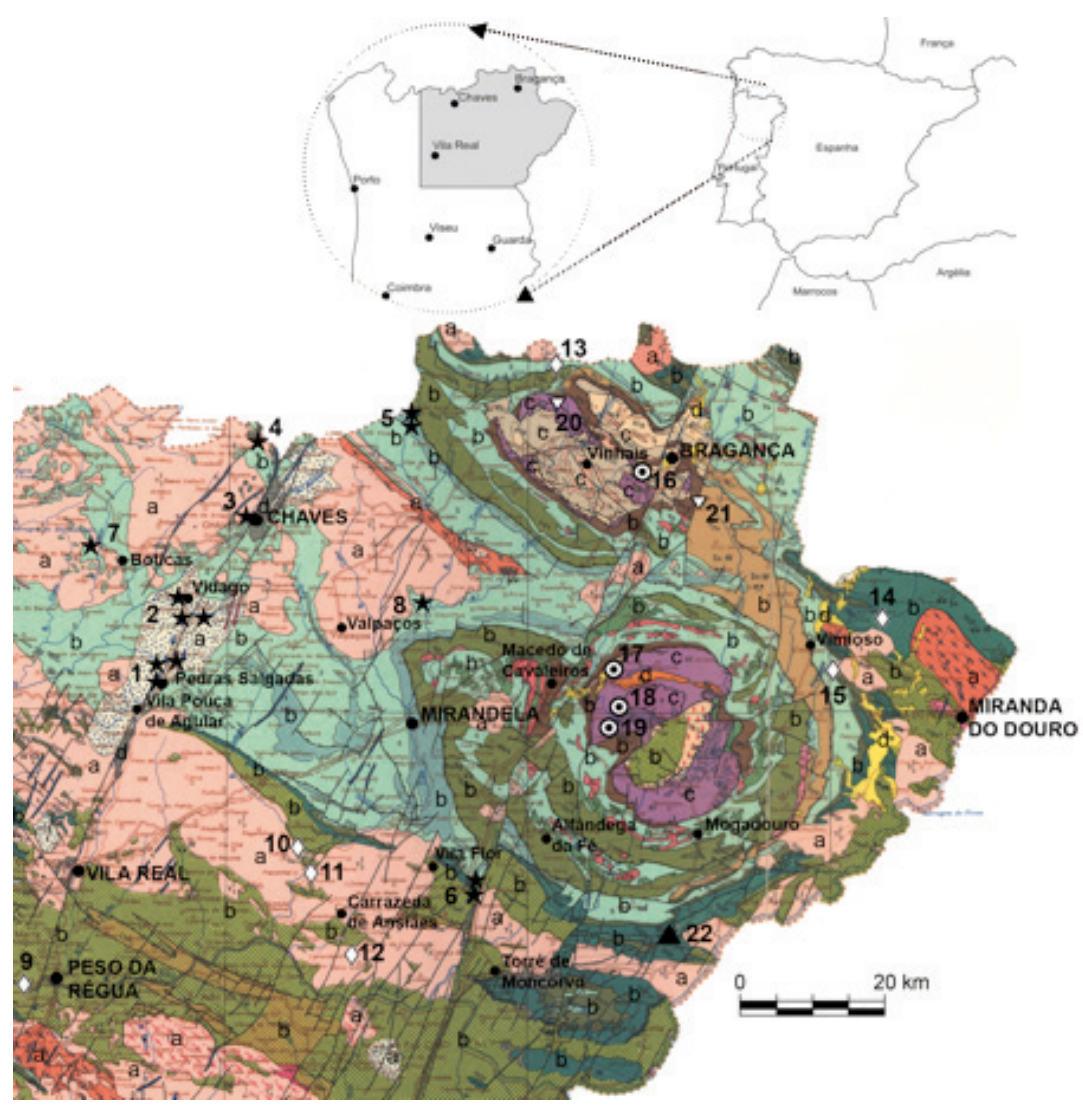

Legenda:

A - Tipologias hidroquímicas / ocorrências:

Família $1(\star)$ 1-Pedras Salgadas/Romanas/Sabroso, 2-Vidago/Salus/Campilho/Salgadela, 3-Chaves, 4-Vilarelho da Raia, 5-Sandim/Segirei, 6-Bem-Saúde, 7-Carvalhelhos, 8-Ribeirinha;

Família $2(\diamond)$ : 9-Moledo, 10-Carláo, 11-São Lourenço, 12-Seixo de Ansiāes, 13-Moimenta, 14-Angueira, 15-Terronha;

Família $3(\odot)$ : $\quad$ 16-Castro de Avelâs, 17-Salselas, 18-Escarledo, 19-Abelheira;

Família $4(\nabla): \quad 20-S .{ }^{\text {ta }}$ Cruz, 21-Alfaiấo;

Família $5(\mathbf{\Lambda})$ : 22-Lagoaça.

B - Geologia:

Rochas granitóides (a); Rochas metassedimentares (b); Rochas do complexo ofiolítico (básicas e ultrabásicas) (c); Rochas sedimentares (d).

Fratura geológica ; Carreamento $\_$_ _

Fig. 1 - Pólos hidrominerais da região de Trás-os-Montes e Alto Douro. (Adaptado de SOUSA OLIVEIRA, 2001); Base geológica: Carta Geológica de Portugal (1992); Escala original 1:500 000. 


\begin{tabular}{|c|c|c|c|c|c|c|c|}
\hline & & 1०ə5 & ' & ' & $x$ & ' & \\
\hline 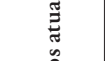 & & 8ua & $\stackrel{\sqrt[3]{x}}{x}$ & $\underset{x}{\sqrt[0]{x}}$ & & ' & \\
\hline 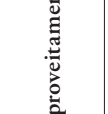 & : & 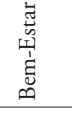 & $\stackrel{\sqrt[3]{x}}{x}$ & ${\underset{x}{a}}_{x}^{a}$ & $x$ & ' & \\
\hline 要 & $\stackrel{\text { }}{\stackrel{\pi}{ٌ}}$ & 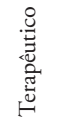 & $\stackrel{\sqrt{x}}{x}$ & 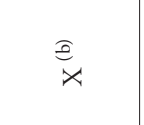 & $x$ & ' & I \\
\hline 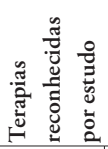 & 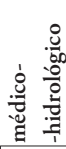 & 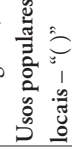 & $\begin{array}{l}0 \\
\hat{v} \\
\hat{n} \\
\hat{i}\end{array}$ & $\begin{array}{l}\hat{n} \\
\hat{n} \\
\hat{n} \\
\hat{n}\end{array}$ & $\begin{array}{l}0 \\
\hat{n} \\
\hat{i} \\
-\end{array}$ & $\begin{array}{l}\tilde{n} \\
\hat{a} \\
\dot{a}\end{array}$ & $\hat{\tilde{n}}$ \\
\hline 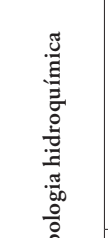 & & & 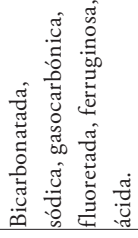 & 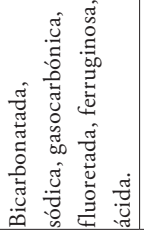 & 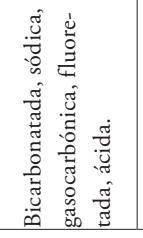 & 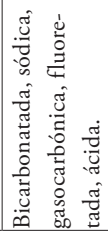 & 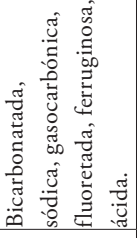 \\
\hline$F$ & & & & & $-\approx$ & & \\
\hline & 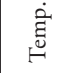 & :0 & $\overrightarrow{\mathbb{A}}$ & તొ & $\stackrel{n}{\wedge}$ & $\begin{array}{l}\stackrel{0}{0} \\
\stackrel{n}{ }\end{array}$ & $\begin{array}{l}\stackrel{0}{n} \\
\stackrel{n}{n}\end{array}$ \\
\hline & 壱 & & ה̂ & $\hat{\sigma}^{n}$ & $\hat{\sigma}$ & $\hat{\sigma}$ & $\overrightarrow{0}$ \\
\hline$\therefore$ 递要 & 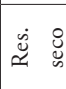 & 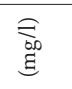 & 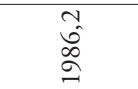 & 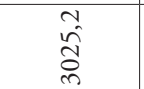 & Oें & $\begin{array}{l}0 \\
\stackrel{0}{N} \\
\stackrel{n}{n}\end{array}$ & $\stackrel{\widehat{A}}{\Xi}$ \\
\hline & 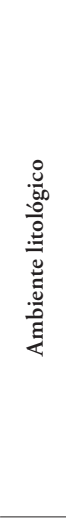 & & 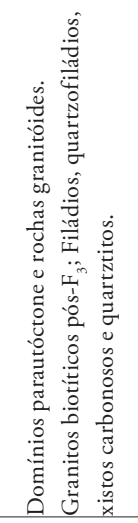 & 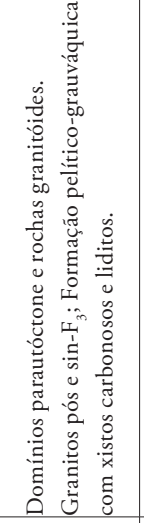 & 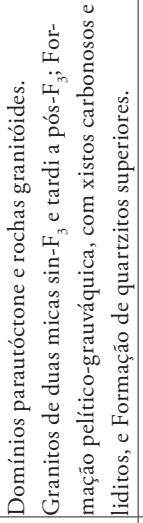 & 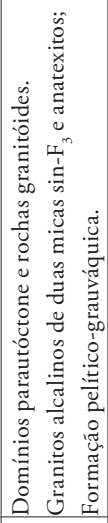 & 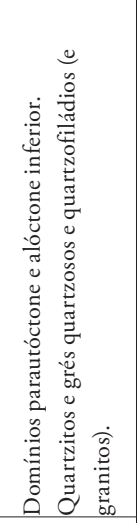 \\
\hline 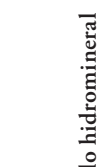 & & 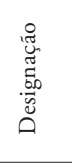 & 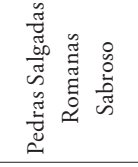 & 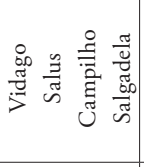 & $\begin{array}{l}\text { 总 } \\
\text { Uू }\end{array}$ & 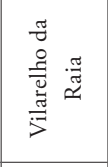 & 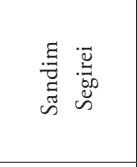 \\
\hline$\stackrel{00}{\circ}$ & & $\ddot{\ddot{~}}$ & - & $N$ & $m$ & $\checkmark$ & in \\
\hline
\end{tabular}




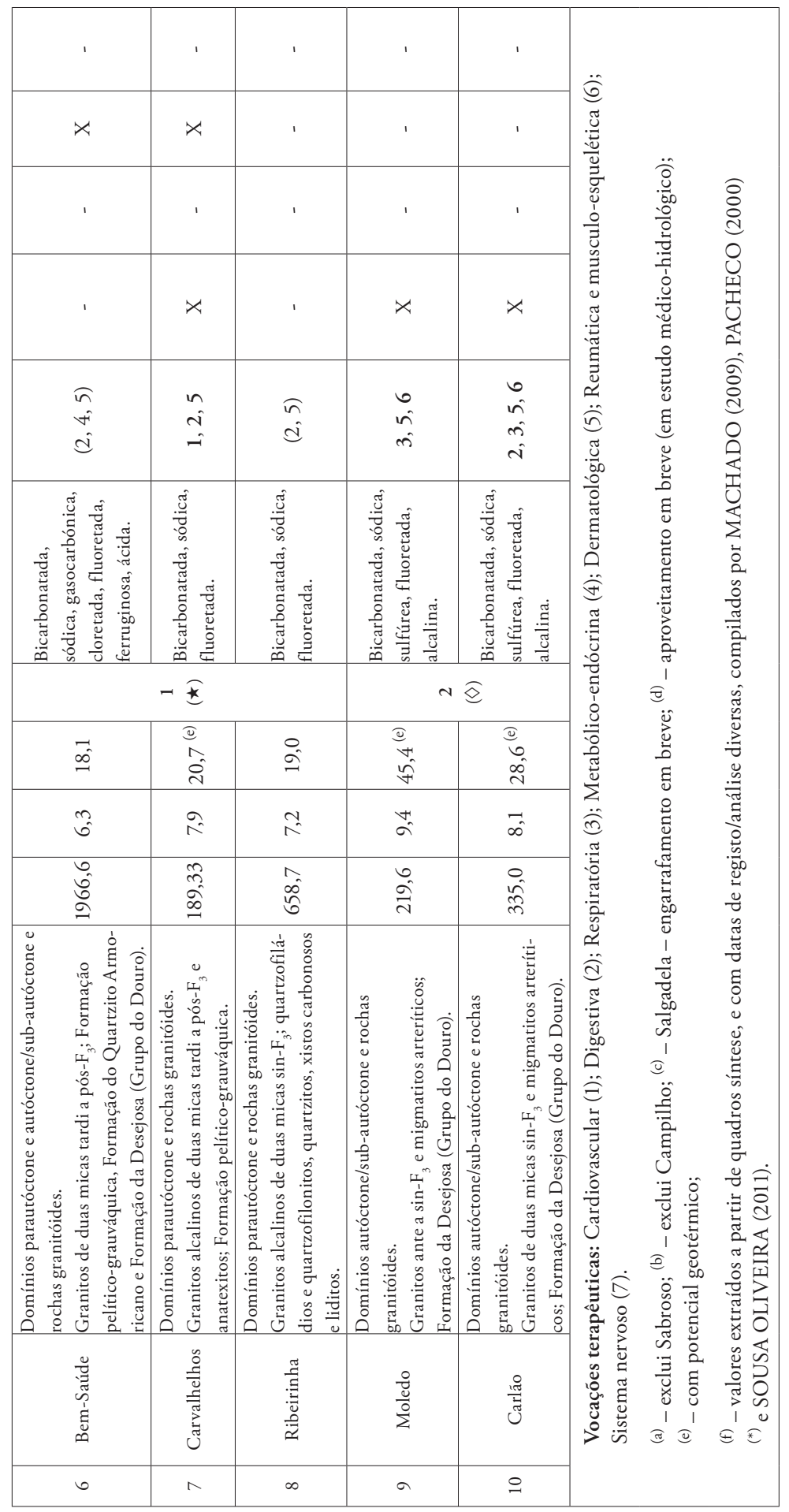




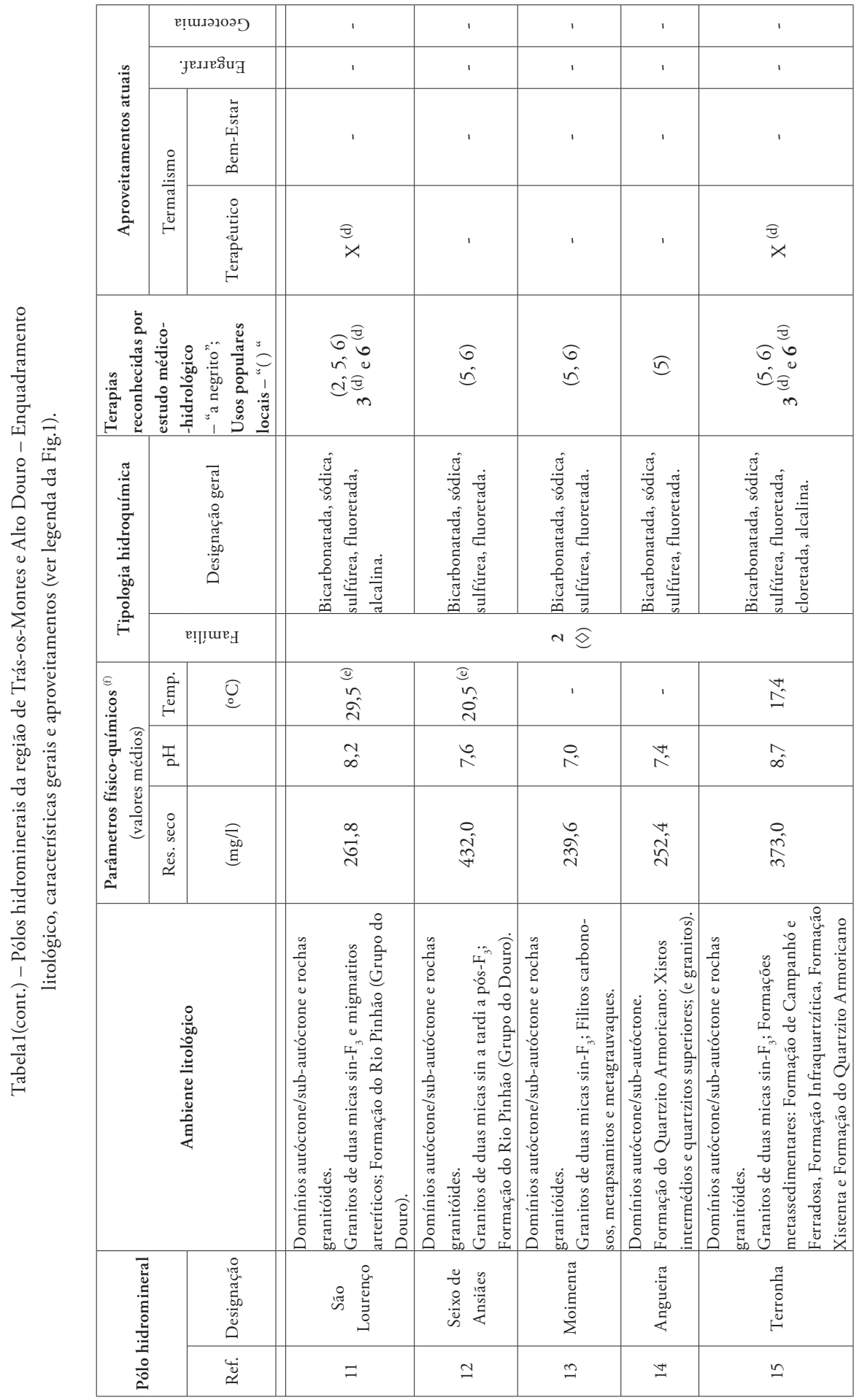




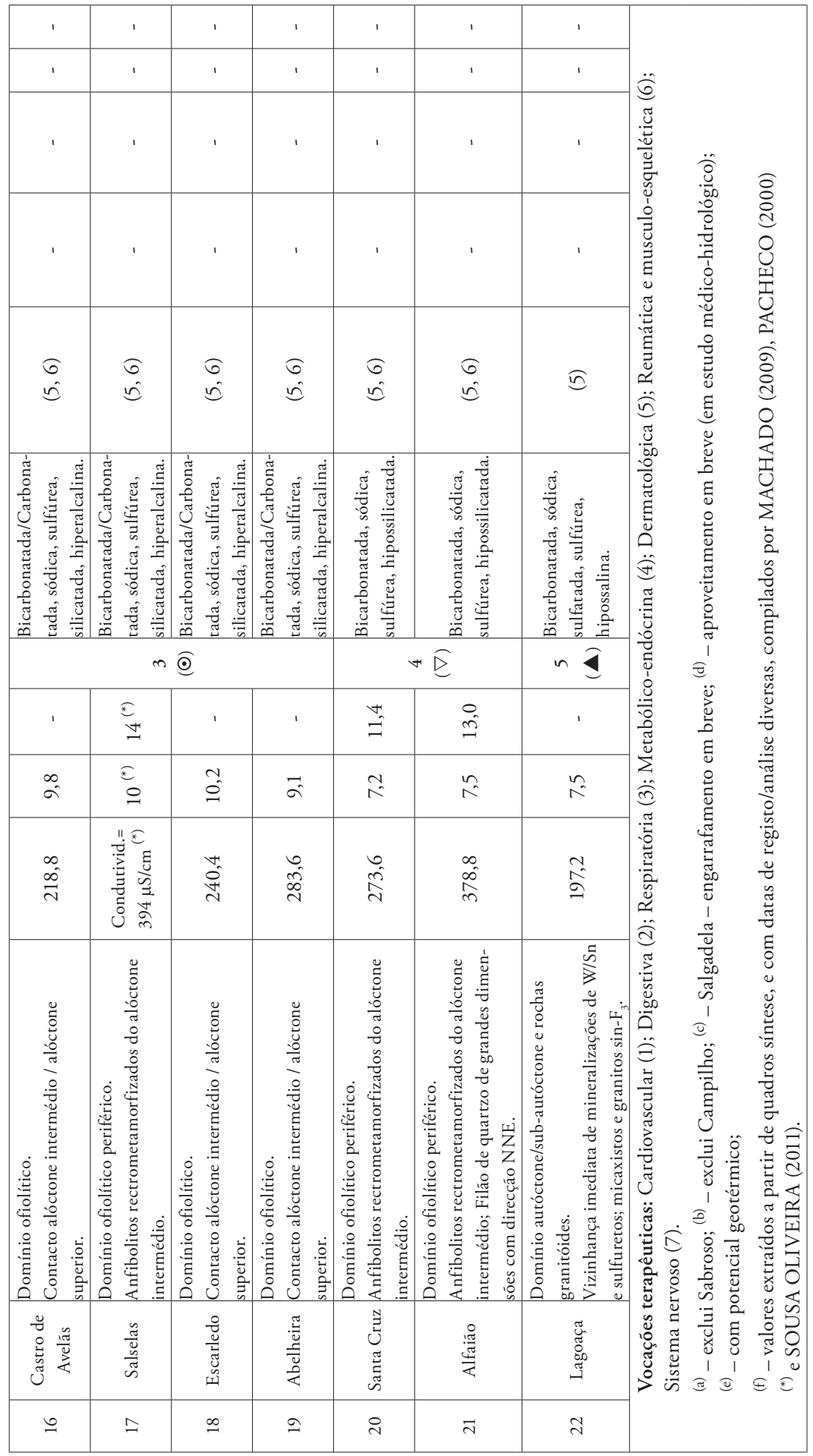


À componente sulfúrea (ou sulfatada) associam-se as águas alcalinas, enquadradas fundamentalmente em ambientes metassedimentares e/ou granitóides.

Do ponto de vista catiónico, o sódio domina em todas as tipologias.

O grupo das águas gasocarbónicas (família 1) manifesta-se por apresentar pH ácido e ocorre fundamentalmente associado a ambientes de natureza granitóide, no contacto de ambiente granitóide/metassedimentar e metassedimentar mas com influência granitóide. Este grupo enquadra-se também no domínio geotectónico do parautóctone transmontano (caso único em Portugal continental), na dependência de grandes fraturas cuja origem ascende aos tempos hercínicos. A origem do $\mathrm{CO}_{2}$, que faz parte integrante da sua composição, tem sido amplamente discutida e os resultados da composição isotópica em $\delta^{13} \mathrm{C}$ apontam para uma origem de natureza principalmente mantélica, embora não sejam de excluir outras contribuições marginais, nomeadamente a partir de litótipos regionais de natureza carbonatada e/ou carbonosa (SOUSA OLIVEIRA, 2001).

\section{4 - Aproveitamentos das águas minerais}

Não obstante o necessário licenciamento das exploraçóes (em Portugal, a concessão de exploração é emitida pela Tutela (Ministério da Economia e do Emprego), desde longa data as diferentes emergências têm sido alvo de aproveitamentos populares, por vezes em infraestruturas rudimentares. Tal pode constatar-se em vários elementos bibliográficos, onde se destacam, por exemplo, HENRIQUES (1726) e ALMEIDA \& ALMEIDA (1970). Pode afirmar-se que a maioria dos polos hidrominerais, e as suas emergências naturais, estão atualmente ditados ao esquecimento ou ao desconhecimento (ver Tabela 1).

Nos casos em que existe exploração, os polos referidos foram intervencionados com o desenvolvimento de captaçóes tubulares, como furos profundos, no sentido de melhorar o caudal de exploração e garantir a qualidade e a proteção deste recurso natural.

Os aproveitamentos situam-se ao nível do engarrafamento em unidades industriais, do termalismo terapêutico e de bem-estar, e ainda ao nível da geotermia. As situaçóes de engarrafamento centram-se nas águas da família das gasocarbónicas, onde também o termalismo é desenvolvido com bastante significado, como é o caso das águas minerais naturais das Caldas de Chaves. Recentemente, nesta família de águas, também Pedras Salgadas abriu ao público um novo espaço termal, no Parque de Pedras Salgadas, que resultou da recuperação e requalificação do antigo balneário. Situação idêntica pode ser referida para Vidago. Os restantes aproveitamentos termais encontram-se associados a águas sulfúreas, sendo que Caldas de Carlão e Caldas de Moledo são os elementos mais representativos; perspetiva-se para breve a abertura de dois novos balneários termais, um localizado em Vimioso, designado Termas da Terronha (ou Termas de Vimioso), e outro em Pombal (Carrazeda de Ansiães), denominado Termas de São Lourenço. Atualmente, as águas de ambos os pólos hidrominerais (Terronha e São Lourenço) encontram-se em fase de estudo avançado, e nos espaços termais estão a desenvolver-se infraestruturas para o seu aproveitamento. Usos rudimentares, normalmente praticados pelas populaçôes da região, são os que se verificam em Abelheira, $S .{ }^{\text {ta }}$ Cruz e São Lourenço (a substituir pelas Termas de São Lourenço).

De um modo geral, as vocaçôes terapêuticas centram-se principalmente no domínio da reumática e músculo-esquelética, respiratória, dermatológica e digestiva (ver Tabela 1). 
Relativamente ao aproveitamento geotérmico, na maioria dos casos a temperatura das águas minerais é inferior a $20^{\circ} \mathrm{C}$, pelo que são consideradas "águas frias". No pólo hidromineral de Chaves ocorrem as águas mais quentes do território continental, com temperatura de aproximadamente $73^{\circ} \mathrm{C}$. O aproveitamento geotérmico é feito principalmente no aquecimento do espaço balnear das Caldas de Chaves, do hotel Aquaflaviae e da piscina municipal, embora o potencial geotérmico possa perspetivar um espetro alargado de utilizaçóes no conceito do aproveitamento geotérmico em cascata. No limite, pode pensar-se na produção de frutos e de outras espécies exóticas, pelo menos na zona de Chaves. Ao nível das águas minerais de Trás-os-Montes e Alto Douro, também é reconhecido potencial geotérmico nos polos hidrominerais de Moledo, Carlão, São Lourenço, Carvalhelhos e Seixo de Ansiães, embora, até hoje, não se tenham aí efetuado quaisquer tipos de aproveitamentos da energia geotérmica nem a qualificação do recurso como geotérmico.

Os polos hidrominerais podem ainda constituir células-âncora para a dinamização e exploração de valências turísticas termais e regionais (associadas ao património da geodiversidade, da biodiversidade, paisagístico, histórico e gastronómico, entre outros), podendo enquadrar o próprio património construído associado aos espaços termais; são exemplo os parques de Pedras Salgadas, Vidago e Moledo, entre outros. A criação de uma "rota, ou rotas, das águas minerais", que articulasse todas estas valências, seria de todo interessante nesta perspetiva.

\section{5 - Consideraçôes finais}

Decorrente principalmente de fatores de natureza geológica, a região de Trás-os-Montes e Alto Douro é impar no panorama dos recursos hidrominerais portugueses, não só pelo elevado número de emergências conhecidas, mas também pela significativa diversidade de tipologias hidroquímicas, que se podem agrupar em 5 famílias principais.

Desde os usos efetuados há longa data em práticas terapêuticas populares, até às modernas práticas de exploração termal e de bem-estar, ao engarrafamento (no caso das águas minerais gasocarbónicas) e à utilização geotérmica (mais recentemente), estas águas têm sido aproveitadas, embora de forma muito desigual. Não obstante a exploração atualmente desenvolvida em alguns polos hidrominerais e o facto de em mais dois polos se estar em fase de pré-exploração, existe um número significativo, se não a maior parte, que se encontra em estado de desconhecimento ou em que a exploraçáo nunca foi devidamente implementada.

O atual interesse dirigido para o património natural antevê novas valências económicas associadas às águas minerais destes polos, nomeadamente no domínio do turismo termal e turismo da natureza, entre outros, que poderão ser promovidas com a criação da "rota, ou rotas, das águas minerais". As especificidades das águas minerais de cada pólo constituem singularidades para a exploração que, aliadas ao contexto patrimonial natural, cultural, construído e outros, potenciam células-âncora de desenvolvimento sócio-económico local e regional.

Agradecimentos - Este trabalho foi realizado com o apoio financeiro do Centro de Geofísica e do Centro de Geociências da Universidade de Coimbra. 


\section{Referências Bibliográficas}

ALMEIDA, A. \& ALMEIDA, J. D. (1970) - Inventário hidrológico de Portugal: Trás-os-Montes e Alto Douro. Instituto de Hidrologia de Lisboa, 2, 639 p.

ANDRADE, M. P. L. (2002) - A geoquímica isotópica e as águas termominerais. Contribuição dos isótopos do $\mathrm{Sr}\left({ }^{87} \mathrm{Sr} /{ }^{86} \mathrm{Sr}\right)$ e do $\mathrm{Cl}\left({ }^{37} \mathrm{Cl} /{ }^{35} \mathrm{Cl}\right)$ na elaboração de modelos de circulação. O caso de algumas águas do $\mathrm{N}$ de Portugal. Tese de mestrado, Universidade Técnica de Lisboa, Instituto Superior Técnico, Lisboa, 104 p.

BRICKER, O. P.; GODFREY, A. E. \& CLEAVES, E. T. (1968) - Mineral-water interaction during the chemical wathering of silicates. Am. Chem. Symp. Ser., Washington, DC: Am. Chem. Soc., 7, p. 128-142.

HENRIQUES, F. F. (1726) - Aquilégio Medicinal. Edição fac-similada (1998). Instituto Geológico e Mineiro. Lisboa.

MACHADO, J. M. G. S. (2009) - Ocorrências hidrominerais do NE de Portugal Continental: inventariação, sistematização e aproveitamentos didácticos. Tese de mestrado em "Biologia e Geologia para o Ensino”. Universidade de Trás-os-Montes e Alto Douro, Vila Real, 469 p.

MARQUES, J. M. V. V. B. (1999) - Geoquímica dos fluídos e da interacção água-rocha: os casos das águas mineralizadas quentes e frias de Chaves, Vilarelho da Raia, Vidago, e Pedras Salgadas. Tese de doutoramento, Universidade Técnica de Lisboa, Instituto Superior Técnico, Lisboa, 276 p.

PACHECO, F. A. L. (2000) - Hidrogeologia em maciços de rochas cristalinas (Morais-Chacim-Macedo de Cavaleiros). Bases para a gestâo integrada dos recursos hídricos da região. Tese de doutoramento, Universidade de Trás-os-Montes e Alto Douro, Vila Real, 395 p.

PORTUGAL FERREIRA, M. \& SOUSA OLIVEIRA, A. (2000) - Lithologic and tectonic control of the mineral waters in the Hercynian Belt: Northeast Portugal. Poster apresentado no $31^{\text {st }}$ International geological congress \& scientific exhibits - geoexpo 2000. 6-17 Agosto, Rio de Janeiro, Brasil.

SERVIÇOS GEOLÓGICOS DE PORTUGAL, Direcção-Geral de Geologia e Minas (1992) - Carta Geológica de Portugal, escala 1:500 000 .

SOUSA OLIVEIRA, A. (2001) - Hidrogeologia dos sistemas gasocarbónicos da Província Hidromineral Transmontana: Ribeirinha (Mirandela), Sandim (Vinhais), Segirei e Salgadela (Chaves). Tese de doutoramento, Universidade de Trás-os-Montes e Alto Douro, Vila Real, 442 p.

SOUSA OLIVEIRA, A. (2011) - Águas minerais naturais de Trás-os-Montes e Alto Douro: património legado pela natureza. In: Escola Secundária Camilo Castelo Branco (eds.). Boletim Cultural, 17, p. 18-29. ISSN $0871-7761$ 